\title{
Os escritores russos na época do populismo
}

\author{
Aurora Bernardini
}

\section{Resumo}

Trata-se de um estudo sobre a assim chamada intelligentsia russa, desde o significado do termo até os feitos de seus componentes. São analisadas as diferentes gerações do populismo russo, da década de 40 até a chegada de Lênin em São Petersburgo, em 1893.

Palavras-chave: Populismo russo, niilismo, rasnotchnítsi, Naródnaia Vólia.

\begin{abstract}
The essay is about the meaning of the expression intelligentsia and its feats in Russia since the first generation of Russian Populists ( 1840), until the arrival of Lenin in Saint Petersburgh in 1893.

Kee-words: Russian Populism, Nihilism, Raznotchnitsy, Narodnaya Volya.

Desde que foi criado, em 1850, pelo escritor russo Boboríkin e tornado famoso pelos romances de Turguêniev, o termo intelligentsia passou a ser adotado em quase todos os idiomas do mundo e utilizado para caracterizar pessoas e circunstâncias bem diferentes das que o haviam originado.

Curiosamente, o termo russo não se refere a certos indivíduos de cultura e expressão privilegiadas, aos quais no ocidente costuma-se dar também o nome de intelectuais e sim a uma categoria social muito peculiar de homens e mulheres, definida por um critério não de classe, mas de consciência.
\end{abstract}


Sua extração social era a mais variada, tendo como denominador comum justamente este peculiar tipo de hibridismo que certos historiadores consideram sintomático. Filhos bastardos de nobres, filhos de servos emancipados que haviam conseguido por certo tempo gozar dos privilégios da classe dominante, estudantes que haviam abandonado a Universidade, seminaristas que haviam deixado a Igreja, parentas enjeitadas de origem aristocrática, em sua grande maioria eram indivíduos que possuíam uma educação, apesar da formação incompleta. Eram os rasnotchnítsi, que em russo significa justamente 'de extração variada'.

Sem linhagem, sem propriedades, sem privilégios, muitos deles recusavam qualquer tipo dé emprego público a serviço da autocracia czarista, em relação à qual mantinham uma atitude perene de declarada e total hostilidade, tendo por outro lado como fonte de inspiração e coesão as forças vitais que emanavam do campo, configurada em um conjunto de valores morais, éticos, filosóficos e políticos que, com o passar dos anos, acabou por conferir-lhes até mesmo certas características físicas peculiares.

A distância entre aristocracia e camponeses não foi preenchida na Rússia daquela época pela burguesia, berço e amparo do intelectual ocidental. 0 único lar da intelligentsia era a visão mental da sociedade idealizada do futuro, uma vez que seu espaço era o de uma constante migração interna, isolada da classe dominante pelo radicalismo e do camponês pela instrução.

A força desta categoria social manifestou-se justamente através do poder que a literatura, a imprensa e a crítica passaram paulatinamente a ter sobre a opinião pública, poder esse de tão grande importância histórica, que não encontrou paralelo em nenhuma outra parte do mundo. Bielínski, Herzen, Tchernichévski, Dobroliúbov, Píssariev, Lávrov, Mikhailóvski - todos eles ideólogos e líderes naturais da intelligentsia -- foram críticos, escritores e/ou editores de revistas.

Esperava-se naturalmente que a literatura veiculasse uma marcada mensagem social e normalmente isso ocorria. Daí as tipificações de heróis, anti-heróis ou "homens supérfluos" que vão de Púchkin a Gontcharov, passando por Lérmontov, Griboiédov e em particular, pela época a que nos referimos, por Turguêniev.

A primeira geração da intelligentsia_russa (começo do séc. XIX) proveio da nobreza. Não por nada, visto que a nobreza era a única classe com meios, não somente de obter instrução, mas de dedicar a vida a ocupações menos prosaicas do que as que envolvem o sustento de uma família. Depois da publicação de Pais e filbos de Turguêniev foi dado a essa geração, que marcou a década de 1840, o nome de "geração dos pais".

Caracterizam-se seus membros por uma certa aversão ao sistema dos servos da gleba, uma certa aura romântica que os leva a acreditarem nos destinos superiores da humanidade, na arte, na razão, na beleza, sob a influência indiscutivel da filosofia idealista alemã de Fichte, Schelling e Hegel. Pável Kirsánov, o tio de Pais e filbos, é bem um modelo dos expoentes dessa geração, cuja influência foi ligeira e difusa, como de curta duração foi sua ascendência espiritual.

Na década de 1850, coincidindo com a humilhação da Guerra da Criméia e com a crise do sistema autocrático escravista, começou a configurar-se um dos primeiros sintomas de uma acentuada mudança na composição da sociedade, justamente no seio da Universidade. Até 1775 , cursá-la tinha sido apanágio da aristocracia, enquanto que na metade do século XIX a maioria dos estudantes universitários vinha de famílias necessitadas: filhos de comerciantes, de camponeses, de artesãos, etc., que, enquanto estudantes, 
eram mantidos pelo Estado. Esses jovens de extração social humilde (raznotchintsi) sentiram brutalmente "na carne" a gritante injustiça social. Em contato com os rebentos de famílias privilegiadas e encontrando-se em grande número na Universidade, começaram a sentir a necessidade de mudanças políticas e sociais, e, assimilando as teorias radicais tanto russas quanto estrangeiras, na década de 1860 já eram um grupo social definido que, juntamente com os filhos de nobres decaídos pertencentes a todas e a nenhuma classe, se originavam do povo e estavam dele afastados, se distanciavam voluntariamente do Estado e assumiam o papel de curadores dos males da Rússia.

A essa geração, a chamada "geração dos filhos" pertence, na literatura, a personagem de Bazárov, o herói de Pais e filbos, o niilista russo que - Turguêniev insiste - foi criado a partir de um tipo real:

\begin{abstract}
"a base da personagem central, Bazárov, apoiou-se sobre a personalidade de um jovem médico de província, falecido pouco antes de 1860 . Nesse homem admirável, encarnava-se -- aos meus olhos - aquele incipiente e ainda embrionário princípio que mais tarde recebeu a denominação de niilismo. A impressão em mim causada por essa personalidade foi muito forte $\mathrm{e}$ ao mesmo tempo pouco clara; nos primeiros momentos, não me dei conta dela e pus-me a escutar intensamente tudo o que estava à minha volta, como que querendo acreditar na veracidade da própria sensação. Perturbava-me o seguinte fato: em nenhuma obra da nossa literatura encontrei jamais sequer um aceno sobre aquilo que me surpreendia em toda parte ...." ${ }^{1}$
\end{abstract}

A "veracidade" do caráter de Bazárov pode ser comprovada numa série de aspectos e, em particular, no elusivo conceito de "povo" que constitui o âmago da ideologia da intelligentsia. Ao mesmo tempo em que ela mantinha uma crença quase mística no camponês (o povo, para os populistas), como portador de uma verdade eterna e genuína, achava que este, deixado a si próprio, era incapaz de libertar-se da opressão e impor uma sociedade mais justa. "O povo - dizia Tchernichévski, um dos mais influentes líderes da intelligentsia russa, por sua vez editor, articulista e escritor - é indiferente à política, é incapaz de uma ação política independente e aspira tão somente a obter vantagens materiais..." (apud Tibor Szamuely The Russian_Tradition p. 155-156) e

"(...) a massa é apenas a matéria bruta para experimentos diplomáticos e políticos. Quem quer que a dirija diz-lhe o que fazer, e ela obedece" (Idem, p. 157).

Sintomática, a consciência dessa contradição, num homem como Tchernichévski que passou vinte e sete anos preso e exilado, sem nunca esmorecer sua dedicação à causa populista, à qual voluntariamente sacrificou sua vida.

Igualmente sintomática é a atitude de Bazárov em relação ao povo, numa série de passagens da mesma maneira 'contraditórias'. Numa delas, em conversa com o amigo Arcádio, ele repara:

"Você, por exemplo, ao passar perto da casa do nosso administrador Felipe, disse: que casinha confortável, simples e limpa.

1 Grifos nossos, retirados de um escrito de Turguêniev "A propósito de Pais e filhos" (1868 - 1869) in Memórias de Vida e de Literatura, Obras Reunidas, Vol. X, Ed. Estatal de Literatura, Moscou, 1962. 
Disse mais: que a Rússia será o melhor país do mundo quando o mais pobre mujique tiver um lar como esse e que cada um de nós deve contribuir para essa conquista (...) pois bem, eu comecei a odiar aquele mujique Felipe ou Sídor que seja, para quem devo fazer o impossível e que não me dirá sequer obrigado ... Que necessidade tenho eu afinal de seu agradecimento? Viverá bem numa casinha limpa e branca e eu andarei sujo, e depois?"'.

E ainda, à p. 246, quando Bazárov já optou pela vida obscura no campo, cuidando das mais simples tarefas junto com o pai médico:

"Às vezes Bazárov se dirigia ao povoado e, em conversa com qualquer mujique, ridicularizava-o como de costume. Vamos dizia-lhe - exponha suas teorias sobre a vida, meu amigo. Dizem que vocês representam todo o futuro e toda a força da Rússia, que vão iniciar um novo período da história, que nos darão linguagem e leis novas". O mujique ou nada respondia ou proferia palavras que significavam mais ou menos as seguintes: "Podemos .... por que ... teremos por acaso uma nova divisão de terras?". - Diga-me, de que espécie é o mundo que concebem? - interrompia-o Bazárov. - Não será o mundo que está apoiado no lombo de três enormes peixes?

- A terra, meu senhor, está de fato apoiada nos três grandes peixes - calmamente e com bondade patriarcal explicava o mujique. - Contra este nosso mundo está a vontade dos senhores. Eis porque os senhores são nossos pais. Quando mais severo é o senhor, mais agrada ao mujique.

Depois de ouvir semelhantes palavras, Bazárov moveu num gesto de desprezo os ombros e foi embora. O mujique também seguiu o seu caminho.

- De que estava falando? - perguntou outro mujique de meia idade e aspecto melancólico, sentado à porta de sua cabana $e$ que vira de longe que ele conversava com Bazárov. - Não será sobre os impostos?

- Que impostos, irmão! - respondeu o primeiro mujique. Na sua voz já não se ouvia aquele acento patriarcal. Percebia-se até certa severidade. - Andava batendo a língua à toa. Por acaso os senhores entendem alguma coisa da nossa vida?

- Que esperança! - replicou o outro mujique. Sacudindo a poeira do chapéu e desapertando um pouco o cinto, começou a discutir sobre os seus negócios e necessidades. Bazárov, tão inteligente, observador e conhecedor dos mujiques (como teve ocasião de afirmar nas discussōes com Pável Petróvitch), esse mesmo Bazárov suspeitava que aos olhos dos mujiques ele não passava de uma espécie de palhaço ....".

Outro aspecto da intelligentsia captado por Turguêniev era a veneração pelas ciências, quase transformada em religião secular. O livro todo está constelado de referências aos experimentos cientíicos de Bazárov, da mesma forma que a vida real está repleta de sequazes do materialismo vulgar de Bichner, Vogt e Moleschott, com sua

2 De Pais e filbos - traduzido por Ivan Emilianovitch, Ed. Livraria Martins, S. P., 1941, p. 4 com algumas modificações da autora do presente texto. 
tendência a reduzir todo fenômeno biológico e social às categorias básicas e mecânicas.

"A ciência, apenas a ciência, é capaz - independente de qualquer fato histórico - de despertar a opinião pública e de moldar os líderes de que nosso país precisa" - escrevia Píssariev, na época. Poderia parecer estranho que a menos transcendente das teorias passasse a ser evocada quase com exaltação fanática, mas para o nilista russo ela abria a perspectiva de um novo mundo científico, cujas diretrizes de justiça absoluta estariam baseadas nas leis imutáveis da natureza.

Ao messianismo e ao cientificismo da década anterior, a década de 70 acrescentou o Darwinismo e o positivismo de Comte.

Só as idéias propaladas no ocidente por Bentham, Spencer e Stuart Mill, baseadas essencialmente no indivíduo, seus direitos e liberdades e, em certa parte, consolidadas em leis políticas, não encontraram eco entre os expoentes radicais da intelligentsia russa.

"O que é esse tão falado sistema de leis européias senão um outro e sofisticado tipo de injustiça?", perguntava o grande Herzen em Na outra margem ${ }^{3}$.

"O interesse do indivíduo deve estar subordinado, de uma maneira ou de outra, ao interesse da sociedade", diz Píssariev.

Este vai se tornando aos poucos na Rússia um dos princípios básicos da intelligentsia radical.

"O cidadão é obrigado a renunciar a algumas de suas aspiraçôes para contribuir a alcançar outras aspirações mais importantes para a sociedade', estipulará Tchernichévski, que, em seu surpreendente romance $O$ que fazer?, de repercussão tão estrondosa e permanente, estabelece os traços já não dos niilistas mas dos "novos homens" cuja tarefa será a de constituir a liderança revolucionária da intelligentsia, dirigindo os esforços da nação para a revolução necessária do povo, para o povo, mas não necessariamente pelo povo.

Essas idéias, apesar da imolação de Tchenichévski à causa, que marcou sua autoridade com o selo da inviolabilidade, tornaram-se o fulcro da divisão no seio da intelligentsia até, praticamente, o advento de Lênin.

Ironicamente, o movimento populista russo foi deslanchado pela lei de Alexandre II da emancipação dos servos da gleba, em 1861, que impunha uma série de cláusulas, um sem número de deveres e obrigações aos servos recém-emancipados.

$\mathrm{O}$ ano de 1861 foi marcado por um grande número de distúrbios. Desde a greve dos universitários, saques, incêndios, até uma série de manifestos lançados aos jovens expondo a plataforma política do populismo (Mikhail Mikháilov) e constituindo o grupo secreto Ziemliá $i$ Vólia (Terra e Liberdade), um de cujos arautos foi Zaichniévski, que marcava a passagem da teoria para a prática revolucionária.

Ao primeiro atentado à vida do czar, pelo grupo ilegal de Ishiutin e Karakózov (1866) segue-se uma das maiores causes celèbres de todos os tempos: o assassinato pelo grupo de Necháiev de Ivanóv, um companheiro de conspiração.

"Quem poderia discernir nisso nossa idéia original?", diz uma personagem dos Demônios de Dostoiévski, onde a figura de Necháiev é reçriada no diabólico Piotr Vierkhoviênski, atribuindo aos pais a culpa pelos filhos.

3 Todas as citaçóes referentes aos populistas são do Autor, na obra citada. 
"Ele é louco e insolente - dizia Herzen (1867) numa carta a Bakúnin referindo-se a um discípulo de Tchernichévski - mas o que me assusta é que a maioria da juventude é igual a ele e que nos a ajudamos a tornar-se assim".

$\mathrm{O}$ affaire Necháiev e suas previsíveis consequiências demovem grande parte da intelligentsia da idéia da conspiração. $O$ homem da década de 70 volta às raízes primeiras do populismo, volta-se novamente para o campo.

"Chegou o tempo - diz Lávrov, o porta-voz dessa fase - para o trabalho calmo e conseqüente, para a atividade paciente e os lances calculados". Surgem de fato círculos de estudo em grande parte das regióes, sendo o mais importante o de Nikolai Tkatchov, do qual participam os revolucionários mais em vista da época, quais Jeliábov, Piotr Kropótkin, Tikhomirov e Sófia Peróvskaia.

Porém, como mostra cruamente Turguêniev em Terras Virgens, o povo não só está distante dos conspiradores, não só não os entende, mas chega a denunciá-los à polícia.

Isso é o que ocorre no chamado "verão louco" de 1874:. Entre os 770 indiciados há apenas 37 camponeses. $\mathrm{O}$ abismo entre povo e intelligentsia é patente. A revolução da maioria, em seu conceito, havia falhado mais uma vez.

Com Tkatchóv volta-se à tradição dos Dekabristas, à já combatida conspiração por parte de uma elite. As discussões ideológicas entre Lávrov e Tkachov, em Zurique, onde ambos estavam refugiados, sucedem-se. Estamos em 1873 . 0 primeiro, apoiado por Engels, insiste em sua revista $V$ period (Avante) na revolução a ser levada adiante pela maioria de grupos politicamente conscientes enquanto o segundo, após uma série de panfletos e uma carta aberta a Engels, onde insiste nas condições particulares da Rússia ( em que há muito vigoravam as comunidades agrárias - desde o ziêmstvo até a óbschina) e na revolução o mais cedo possível, sem a eterna espera das "circunstâncias favoráveis", lança seu próprio periodico com o sugestivo nome de Nabat (toque a rebate), onde difunde novamente entre os jovens as teses jacobinas: centralização/ disciplina/rapidez da decisão/unidade de ação.

Assim se alternam as polêmicas nos primeiros anos da década de 70 , fora $\mathrm{e}$ dentro da Rússia, pois a literatura 'subversiva' era a verdadeira ordem do dia, até que o affaire Chiríguin (1876-1877), o embuste das Milícias Secretas contra Stepanóvitch e Deutsch que teve considerável repercussão junto aos camponeses, defina a cisão no seio do movimento populista entre terroristas e populistas.

O partido terrorista Ziemliá $i$ Vólia que se formou, teve dezoito meses de existência. Núcleos revolucionários foram disseminados pelas religiões, aparições públicas foram realizadas, até que a polícia acabou por desativar seus membros, prendendo a maioria de seus adeptos.

A questão dos Balcãs, com a declaração da guerra aos turcos por parte da Rússia em 1977, reuniu os populistas em torno da "causa eslava". Muitos deles se engajaram para lutar a favor dos Sérvios e voltaram com novo senso de unidade e de solidariedade.

Os processos aos vários presos das atividades populistas realizam-se com grande repercussão. Terminada a guerra, no "processo dos 50" (março de 78) e no "processo dos 193" (janeiro de 79), muitos são sentenciados e alguns são soltos, entre os quais os futuros matadores do czar, Jeliábov, Peróvskaia, Sáblov, além de Tikhomírov e Morózov. Disso tudo resulta uma fusão e uma nova estratégia de violência revolu- 
cionária.

Em 24 de janeiro de 78, Vera Zassúlitch atira contra o governador de São Petersburgo; em 30 de janeiro, Kováski e seu grupo trocam tiros com a polícia (Comitê Executivo do Partido Populista Revolucionário); em 4 de agosto, Serguei Krávchinski mata o Chefe da polícia secreta; em 2 de abril de 79, Soloviov atenta contra a vida do czar.

Se a esses atentados se somarem os movimentos de protesto dos estudantes em várias capitais, a reorganização do partido Ziemliá $i$ Vólia com seu programa, onde consta como único método possível de luta política o terrorismo, pode-se ter uma idéia da quase paralisia em que se encontra o governo diante da variedade das provocações.

Entretanto, em junho de 79, há o congresso dos populistas em Vorónei, onde se discutem novamente as questões básicas de organização e atuação (revolução política $\mathrm{x}$ revolução social) e que, após encerrado, implica uma última divisão populista, antes do projeto do atentado ao czar ser bem sucedido.

O grupo que veio a chamar-se Tchorni Perediel (Partilha Negra) com Stefanóvitch e Deutsch e, curiosamente, Vera Zassúlitch, a iniciadora da campanha terrorista, entre outros, era o grupo pacífico, liderado por Plekhánov, que iniciará a difusão do Marxismo na Rússia.

O outro grupo, o da Naródnaia Vólia, ao qual se juntaram Peróvskaia e Jeliábov, entre outros, viria a tornar-se o movimento que representaria o triunfo final dos princípios dos jacobinos Zaichniévski, Necháeiv e Tkachov. Eis, resumidos, os princípios básicos distribuídos entre os membros em 1880:

"A organização da Naródnaia Vólia consiste numa rede de pequenos círculos unidos por finalidades revolucionárias comuns; está baseada nos princípios de centralização dos grupos de nível inferior em volta dos de nível superior, que será , a cada vez, complementado pela absorção dos melhores elementos dos grupos inferiores. A inteira organização do partido tem um único centro comum: o Comitê Executivo".

No programa, a análise da situação da Rússia era análoga ao argumento que outrora Tkatchov utilizara em sua carta aberta a Engels. O objetivo proposto era de uma franqueza total: "Nossa tarefa imediata é a de libertar o povo do jugo opressivo do Estado atual e realizar um golpe político que visa dar o poder ao povo".

Após realizar um levantamento real das possibilidades, o Comitê Executivo resolveu concentrar as forças num único objetivo: o assassinato de Alexandre II. Após quatro tentativas, que redundaram na prisão de Aleksander Mikháilov e Jeliábov, Sófia Peróvskaia assumiu a operação. Em 1 de março de 1881 o czar estava morto; em 3 de abril os organizadores diretos do atentado eram enforcados; em 1883 Naródnaia Vólia deixou de existir. A revolução não ocorreu, mas o desenvolvimento burguês da Rússia havia sido abalado.

A época que se segue, do curto reinado de Alexandre III até a guerra do Japão de 1904, é das mais retrógradas que se conhece na história da Rússia, apesar da industrialização e do óleo de Baku. A agricultura está estagnada. A Universidade amordaçada pelo inflexível Pobiedonóssiev. Lóris-Mélikov refere-se continuamente a reformas que nunca serão feitas. Há programas anti-semitas em todas as regiōes e, anacronicamente, diante do aparente bem-estar do "mundo civilizado ocidental", a fome e o cólera grassam na Rússia.

Apesar da contínua censura e do asfixiante paternalismo burocrático que tudo esmorece, fala-se, fala-se muito. Quanto à intelligentsia, percebe-se que o Marx- 
ismo teve uma grande influência. Tikhomírov, um dos últimos populistas que sobreviveram, envia do estrangeiro uma carta ao czar renegando seus princípios e pedindo sua readmissão social.

Um grupo de brilhantes professores universitários, os assim chamados "Marxistas legais" - Struve, Tugan-Baranóvski, Berdiáiev, Bulgákov (que depois de torna um dos teóricos do existencialismo russo) e outros -- reúnem-se e discutem as teorias marxistas.

Outro grupo de igual tendência, "A emancipação da Rússia", visita Plekhánov no exterior e com ele publica legalmente na Rússia, pela primeira vez, sua análise marxista da sociedade russa "Sobre a questão do desenvolvimento da visão monística da história", que se esgota em três semanas.

A industrialização estava realmente criando um sistema de relações de produção capitalista, conforme Plekhánov previra: era a base capitalista à espera de sua superestrutura. Assim aconteceria, a seu tempo, pensava Plekhánov, com a criação de uma base e conseqüente superestrutura socialista. A tarefa agora seria a de preparar esse dia e disseminar as iúéias socialistas o mais amplamente possível. Só que no caso da Rússia, Plekhánov não vira aquilo que Tkátchov e os narodovóltsi descobriram uma década antes: o Estado, enquanto parte da assim chamada superestrutura, sempre havia sido o responsável pela criação da base econômica, e não o contrário, na Rússia.

Tchékhov é o grande escritor dessa época. Diante da inviabilidade da vida russa, suspiram as personagens de suas peças, na cidade e no campo: "Talvez daqui a cem ou a duzentos anos isso aqui mude". Mas a par disso, ele escrevia "A enfermaria número 6", um conto tão caro a Lênin, como outrora o fora "O que fazer" de Tchenichévski. O cataclismo era inevitável. Não se podia mais continuar assim.

Onde falhou o panfleto dos populistas, radicais ou menos, não foi na preparação de seu advento, mas na ênfase que sempre deram ao papel a ser desempenhado pelo campo,

A força viva em que Vladímir Ilich Uliánov, um obscuro advogado de Samara recém-chegado em S. Petersburgo em 1893, se apoiará, para o progresso industrial e a revolução incipiente, será, ao contrário, o proletariado. 